University of Nebraska - Lincoln

DigitalCommons@University of Nebraska - Lincoln

Faculty Publications: Department of Entomology

1987

\title{
Comparison of Gelled and Meat Diets for Rearing Screwworm, Cochliomyia hominivorax (Diptera: Calliphoridae), Larvae
}

\author{
David B. Taylor \\ University of Nebraska-Lincoln, dave.taylor@ars.usda.gov \\ Robert L. Mangan \\ USDA-ARS, Chiapas, Mexico
}

Follow this and additional works at: https://digitalcommons.unl.edu/entomologyfacpub

Part of the Entomology Commons

Taylor, David B. and Mangan, Robert L., "Comparison of Gelled and Meat Diets for Rearing Screwworm, Cochliomyia hominivorax (Diptera: Calliphoridae), Larvae" (1987). Faculty Publications: Department of Entomology. 213.

https://digitalcommons.unl.edu/entomologyfacpub/213

This Article is brought to you for free and open access by the Entomology, Department of at DigitalCommons@University of Nebraska - Lincoln. It has been accepted for inclusion in Faculty Publications: Department of Entomology by an authorized administrator of DigitalCommons@University of Nebraska - Lincoln. 


\title{
Comparison of Gelled and Meat Diets for Rearing Screwworm, Cochliomyia hominivorax (Diptera: Calliphoridae), Larvae ${ }^{1}$
}

\author{
DAVID B. TAYLOR AND ROBERT L. MANGAN
}

\author{
Agricultural Research Service, U.S. Department of Agriculture, \\ Screwworm Research, Apartado 544, \\ Tuxtla Gutierrez, Chiapas, Mexico
}

\begin{abstract}
J. Econ. Entomol. 80: 427-432 (1987)
ABSTRACT A liquid diet solidified with an acrylamide-acrylate polymer gelling agent (Water-Lock) was compared with a standard meat diet for rearing serewworm, Cochliomyia hominivorax (Coquerel), larvae. Size and yield of larvae reared on gel diet were equal to, or greater than, those of larvae reared on meat diet. Duration of larval development was increased by ca. $13 \mathrm{~h}$ on gel diet; however, variability of pupal weight and larval survival over generations were reduced when gel diet was used. Larval size was also more uniform over the 3 -d period when larvae leave the rearing medium to pupate (crawl-off). Gelled diet was more uniform over time than meat diet. In addition, gelled diet was easier to use, less objectionable to workers, and less expensive than meat diet.
\end{abstract}

KEY WORDS Cochliomyia hominivorax, larval diets, gelling agents, mass-production, rearing

THE LARVAL DIET currently used for screwworm, Cochliomyia hominivorax (Coquerel), research is a modification of the meat diet developed by Melvin \& Bushland (1936, 1940). A liquid diet developed by Gingrich et al. (1971) and modified by Brown \& Snow (1979) has been used for $12 \mathrm{yr}$ to mass-rear screwworm larvae for the United States and Mexico screwworm eradication programs. However, the liquid diet has not been adapted for research rearing because it is not well suited for rearing discrete lines in small groups. Harris et al. (1984, 1985) reported a serewworm larval diet prepared by solidifying the liquid diet of Gingrich et al. (1971) with a sodium polyacrylate, polyacrylamide polyacrylate copolymer (Water-Lock) suitable for rearing screwworm larvae. The gelled diet compared favorably with respect to larval size and survival with a meat diet used for screwworm research and the liquid diet used for mass production.

Our study compared gelled and meat diets with respect to larval survival, pupal weight, adult emergence, sex ratio, fecundity, and fertility during five generations. Distributions of larval weights during the 2- to 3-d period during which larvae leave the rearing medium to pupate (crawl-off) were examined. Comparisons were also made between two different formulations of the gelling agent and between several strains of screwworm flies.

${ }^{1}$ This article reports the results of research only. Mention of a proprietary product does not constitute an endorsement or a recommendation for its use by USDA.

\section{Materials and Methods}

The study consisted of three experiments. In the first, we examined life-history parameters for screwworm lines reared on meat or gelled diets for five generations. In the second experiment, we examined larval-fitness parameters for larvae reared for one generation on meat or on one of two gelled diets. In the third experiment, we compared larval-fitness parameters within a generation using a gelled and a meat diet to rear newly colonized isofemale lines. The basic methods of preparing media and rearing the larvae were identical in all tests. For each plastic rearing pan (19 by 16 by $9 \mathrm{~cm}$ deep), 2 liters of diet was used. Freshly oviposited eggs were incubated in plastic petri dishes $(9 \mathrm{~cm})$ at $35^{\circ} \mathrm{C}$ for $24 \mathrm{~h}$ with a small amount (ca. $5 \mathrm{~g}$ ) of horse meat in each dish with the eggs (day 0 ). Pans were infested with $100 \mathrm{mg}$ of eggs (ca. 2,700 eggs) for the first experiment. In the other two experiments, pans were infested with $50 \mathrm{mg}$ of eggs (ca. 1,350 eggs). Upon eclosion, larvae entered the meat, which was then placed on the rearing media.

Larvae on the two diets were treated as equally as possible with respect to ambient conditions. Meat groups were initiated (1st d) with 0.5 liter of starting meat diet $(1.3 \mathrm{~kg}$ lean ground horse meat $/ 30$ $\mathrm{g}$ dried $\mathrm{egg} / 30 \mathrm{~g}$ dried nonfat milk $/ 1.5 \mathrm{ml}$ formalin/ 1 liter water). On the 2nd and 3rd d, pans were provided with 0.5 and 1 liter, respectively, of a finishing medium (1.3 kg ground horse meat/ $50 \mathrm{~g}$ dried bovine blood $/ 1.5 \mathrm{ml}$ formalin/1 liter water). Used medium was collected and discarded immediately before each feeding. 
Gelled diet groups were initiated with 0.5 liter of gelled medium $(70 \mathrm{~g}$ dried blood $/ 30 \mathrm{~g}$ dried egg/ $30 \mathrm{~g}$ nonfat dried milk/ $1.5 \mathrm{ml}$ formalin $/ 15 \mathrm{~g}$ gelling agent/1 liter water) on the 1 st $d$, not fed on the 2 nd $d$, and then provided 0.5 and 1 liter of the gelled medium on the $3 \mathrm{rd}$ and $4 \mathrm{th} \mathrm{d}$, respectively. Water-Lock G-400 gelling agent was used throughout the test unless otherwise specified. Used or waste gelled diet was not removed from the pans. Fresh diet was simply added on top of the old.

Larval pans (meat and gel) were incubated in open, heated water baths. The water temperature was maintained at $39^{\circ} \mathrm{C}$. When mature larvae were observed crawling on the surface of the medium, rearing pans were removed from the heated water bath, placed in plastic trays $(24$ by $20 \mathrm{~cm}$ ) containing sawdust ( $2 \mathrm{~cm}$ deep), and maintained at room temperature $\left(25^{\circ} \mathrm{C}\right)$. Larvae crawled out of the rearing pans (crawl-off) and pupated in the sawdust.

For the first test, lines were maintained for five generations on gelled and meat diets. Rearing pans were removed from the sawdust trays $5 \mathrm{~d}$ after crawl-off began. Pupae were sifted from the sawdust on the following day, and the total volume of pupae produced from each pan was measured. A sample $(10 \mathrm{ml})$ of pupae was taken and weighed, and number of pupae in the sample was recorded. These values were used to calculate mean weight of the pupae (weight per $10 \mathrm{ml} /$ number of pupae per $10 \mathrm{ml}$ ), total volume of pupae, and total number of pupae ([number of pupae per $10 \mathrm{ml} / 10] \times$ total volume). The same $10-\mathrm{ml}$ sample of pupae was placed in a small, closed plastic cup to determine percent emergence and sex ratio. Pupae (broodstock; $50 \mathrm{ml}$ ) were placed in a wire cage (15 by 30 by $12 \mathrm{~cm}$ ) and, upon emergence, adults were provided with honey and water. Oviposition was elicited $8 \mathrm{~d}$ after emergence by placing an oviposition cup (a small, covered plastic cup filled with warm water with ca. $50 \mathrm{~g}$ of ground horse meat on top) in the cages. The cages were then placed for $1 \mathrm{~h}$ in a darkened room maintained at $40^{\circ} \mathrm{C}$. Total weight of eggs recovered from each cage was recorded; $100 \mathrm{mg}$ was used to initiate the subsequent generation. Percent eclosion was determined from a random sample of ca. 500 eggs. Each diet was replicated four times for each generation.

The outerossed line used for this comparison originated from the VF-84 strain, which was developed by the systematic crossing of 16 isofemale lines (lines derived from single field-collected egg masses) collected near Villa Flores, Chiapas, Mexico. The VF-84 strain had been reared on the meat diet continuously for ca. 25 generations.

Three diets (meat and two formulations of Water-Lock gelling agent) were compared in the second experiment. The two gelling agents differed in uniformity of the grain size and appeared to have different absorptive capacities. The more expensive type (G-400) was more uniform and of finer texture than the cheaper variety (G-100). Four replicates from the VF-84 strain were reared for a single generation on each of the three diets for a total of 12 pans. Beginning on the 4 th $d$, larvae were sifted from the sawdust every $2 \mathrm{~h}$ for $72 \mathrm{~h}$ (36 samples). Total larval weight and number of larvae for each sample were recorded. Development time was calculated as the unweighted mean of the total hours elapsed from initiation of the pan until the sample was taken. Mean development time was a mean of the developmental times for all sample periods producing one or more larvae.

In the third experiment, we examined rearing characteristics of nine isofemale lines on the gelled and meat diets. The isofemale lines were collected near Chetumal, Quintana Roo, Mexico, in July 1984 and used in these tests in September 1984 after two generations of rearing on the laboratory (meat) diet. Tests with each line were replicated twice on each diet for a total of 36 pans. Larvae were handled the same as in the second experiment and data were recorded separately for each pan, thus permitting the variability in rearing characteristics attributable to the isofemale lines to be calculated.

A two-level nested analysis of variance (ANOVA) was used to analyze the effect of diet and generation on the biological parameters examined in the first experiment. The effect of generation within each diet was analyzed with a one-way ANOVA. Linear regression was utilized to detect linear trends in the biological parameters over generations. For the second experiment, effects of diet were analyzed using ANOVA and multiple analysis of variance (MANOVA). The ANOVA tested significance of the three diets for number of larvae produced, development time, and larval weight separately. These three measurements are likely to interact (personal observation), so a MANOVA test that determined the significance of treatments on the three interacting response variables was performed. Methods for calculation of the test statistics were given in Wilkinson (1985, 181-261) and Morrison (1976). A 2-way analysis of variance was used to determine the effect of diet and isolines on the number of larvae pupating, mean time to crawl-off, and average larval weight for the third experiment. Calculations were performed (Wilkinson 1986) on a computer (DEC Rainbow 100 or IBM-PC).

\section{Results}

Results from experiment 1 are presented in Table 1 . The mean number of pupae, pupal weight, percent emergence, and weight of eggs oviposited were all higher, although not significantly so, in the gelled-diet groups than in the meat-diet groups (Table 2). Mean percentage of female flies was within $1 \%$ of the expected $50 \%$ for both diets. Mean percent egg eclosion was higher for the meat diet, 
Table 1. Biological parameters of serewworms reared on gelled and meat diets

\begin{tabular}{clrcccc}
\hline \hline Generation & Diet & $\begin{array}{c}\text { No. of pupae } \\
(\bar{x}[\text { SD] })\end{array}$ & $\begin{array}{c}\text { Pupal wt in mg } \\
(\bar{x}[\text { SD] })\end{array}$ & $\begin{array}{c}\text { \% emergence } \\
(\bar{x}[\text { SD] })\end{array}$ & $\begin{array}{c}\text { Eggs (g) } \\
\text { oviposited } \\
(\bar{x}[\text { SD] })\end{array}$ & $\begin{array}{c}\text { \% eclosion } \\
(\bar{x}[\text { SD] })\end{array}$ \\
\hline 1 & Meat & $879.7(284.9)$ & $61.7(4.91)$ & $91.0(1.68)$ & $0.152(0.151)$ & $87.5(5.09)$ \\
& Gelled & $1,076.9(418.4)$ & $52.3(1.69)$ & $93.9(1.81)$ & $0.052(0.030)$ & $84.3(4.48)$ \\
2 & Meat & $1,139.6(269.3)$ & $51.7(2.83)$ & $96.5(4.21)$ & $0.301(0.097)$ & $91.7(2.36)$ \\
& Gelled & $724.5(89.4)$ & $59.0(5.45)$ & $96.9(3.83)$ & $0.160(0.128)$ & $85.0(5.83)$ \\
3 & Meat & $1,121.7(259.4)$ & $46.9(6.72)$ & $96.0(1.35)$ & $0.127(0.122)$ & $80.0(6.00)$ \\
& Gelled & $976.2(161.7)$ & $53.9(1.34)$ & $95.5(3.35)$ & $0.862(0.150)$ & $79.8(1.66)$ \\
4 & Meat & $456.1(187.9)$ & $54.4(4.79)$ & $79.3(9.14)$ & $0.616(0.407)$ & $91.2(7.63)$ \\
& Gelled & $820.0(233.1)$ & $55.1(4.28)$ & $87.6(4.45)$ & $0.474(0.337)$ & $91.1(4.01)$ \\
5 & Meat & $770.0(325.2)$ & $51.2(6.50)$ & $91.7(2.64)$ & $0.166(0.097)$ & $86.2(4.79)$ \\
& Gelled & $983.2(44.4)$ & $53.1(1.92)$ & $97.1(1.69)$ & $0.239(0.165)$ & $86.2(4.79)$ \\
& Meat & $873.4(352.1)$ & $53.2(6.92)$ & $90.9(7.64)$ & $0.273(0.264)$ & $87.3(6.52)$ \\
& Gelled & $916.2(242.4)$ & $54.7(3.84)$ & $94.2(4.57)$ & $0.357(0.341)$ & $85.3(5.38)$ \\
\hline
\end{tabular}

but again not significantly so. Although none of the parameters varied significantly among diets, all, with the exception of sex ratio, differed significantly among generations within diets. Total number of pupae and mean pupal weight varied significantly among generations for the meat diet, but did not vary significantly among generations for the gelled-diet groups. Percent emergence and weight of eggs oviposited varied significantly among generations for both diets. Variation in percentage of eggs hatching was marginally significant for both the meat and gelled diets $(P=0.051$ and 0.035 , respectively). None of the parameters varied linearly with respect to number of generations on the $\operatorname{diet}(P>0.05)$.

The mean number of larvae (50 mg of eggs), development time, and mean larval weight for experiment 2 are shown in Table 3 . The meat diet produced the most larvae, but diet was not a significant factor in determining larval production per pan. Development time was significantly longer on the gelled diets than on the meat diet $(F=$ 38.09; $\mathrm{df}=2,9 ; P<0.001)$. Larvae reared on

Table 2. F values for ANOVA's comparing gelled and meat diets and generations within each diet

\begin{tabular}{|c|c|c|c|c|}
\hline \multirow{5}{*}{ Parameter } & \multirow{2}{*}{\multicolumn{2}{|c|}{$\begin{array}{c}\text { One-way ANOVA } \\
\text { among } \\
\text { generations }\end{array}$}} & \multicolumn{2}{|c|}{$\begin{array}{c}\text { Two-level nested } \\
\text { ANOVA }\end{array}$} \\
\hline & & & \multirow{2}{*}{$\begin{array}{c}\text { Among } \\
\text { diets }\end{array}$} & \multirow{3}{*}{$\begin{array}{c}\text { Among } \\
\text { genera- } \\
\text { tions } \\
\text { within } \\
\text { diets }\end{array}$} \\
\hline & Meat & Gel & & \\
\hline & \multirow{2}{*}{$\begin{array}{c}F \\
(\mathrm{df}= \\
4,15)\end{array}$} & \multirow{2}{*}{$\begin{array}{c}F \\
(\mathrm{df}= \\
4,15)\end{array}$} & \multirow{2}{*}{$\begin{array}{c}F \\
(\mathrm{df}= \\
1,8)\end{array}$} & \\
\hline & & & & $\begin{array}{c}F \\
(\mathrm{df}= \\
8,30)\end{array}$ \\
\hline No. of pupae & $4.38^{a}$ & 1.50 & 0.09 & $3.17^{a}$ \\
\hline Pupal wt & $4.24^{a}$ & 2.45 & 0.30 & $3.73^{a}$ \\
\hline$\%$ emergence & $8.52^{a}$ & $5.84^{a}$ & 0.85 & $7.68^{a}$ \\
\hline$\% 98$ & 1.71 & 2.03 & 0.15 & 1.88 \\
\hline Wt of eggs & $3.72^{a}$ & $11.50^{a}$ & 0.25 & $7.21^{a}$ \\
\hline \% eclosion & 3.03 & $3.42^{a}$ & 0.53 & $3.19^{a}$ \\
\hline
\end{tabular}

${ }^{a} P<0.05$.
G-400 gelled diet were significantly larger than those reared on either the G-100 gelled or meat diets.

We expected the VF-84 strain to be homogeneous genetically because of the relatively long time that it had been reared in the laboratory. Mean larval weight among the samples (taken every $2 \mathrm{~h}$ ) ranged from 40.0 to $80.1 \mathrm{mg}$ for the meat diet, from 55.4 to $81.0 \mathrm{mg}$ for the G-400 gelled diet, and from 46.4 to $75.2 \mathrm{mg}$ for the G-100 gelled diet. Given this range in larval weight during the crawl-off period, a profile of larval sizes during the crawl-off period is needed for experimental designs and quality-control programs requiring samples (rather than weighing all larvae) for estimation of larval size. The largest larvae migrated from the meat diet for a period of 25-40 $\mathrm{h}$ after the beginning of crawl-off (Fig. 1). Mean sample weight then declined steadily during the next 60 h. For the G-400 gelled diet, crawl-off weight increased from 20 to $40 \mathrm{~h}$, then changed little during the next ca. $50 \mathrm{~h}$. Size of larvae on G-100 gelled diet (not shown) followed essentially the same pattern as on G-400 gel but with greater variation.

Weighted and unweighted mean sample weights for experiment 3 are given in Table 4. Since percent eclosion was not scored for this test, the apparent correlation of total number of larvae between diets could be the result of variable egg sterility between lines. Analysis for effects of diet and isolines on number of larvae pupating, mean time for development, and average weight were performed. Diet (meat or gelled) was not significant in determining average larval weight $(F=$ $0.23 ; \mathrm{df}=1,34 ; P=0.63$ ), although lines reared on meat were slightly larger than those reared on gel. Gelled diet produced ca. $26 \%$ more total larvae than the meat diet, but the effect was not significant $(F=2.89 ; \mathrm{df}=1,34 ; P=0.10)$. The effect of diet on average development time was highly significant $(F=22.38 ; \mathrm{df}=1,34 ; P<0.001)$. Larvae reared on meat required an average of $63.25(\mathrm{SD}=5.02) \mathrm{h}$ for development while larvae 


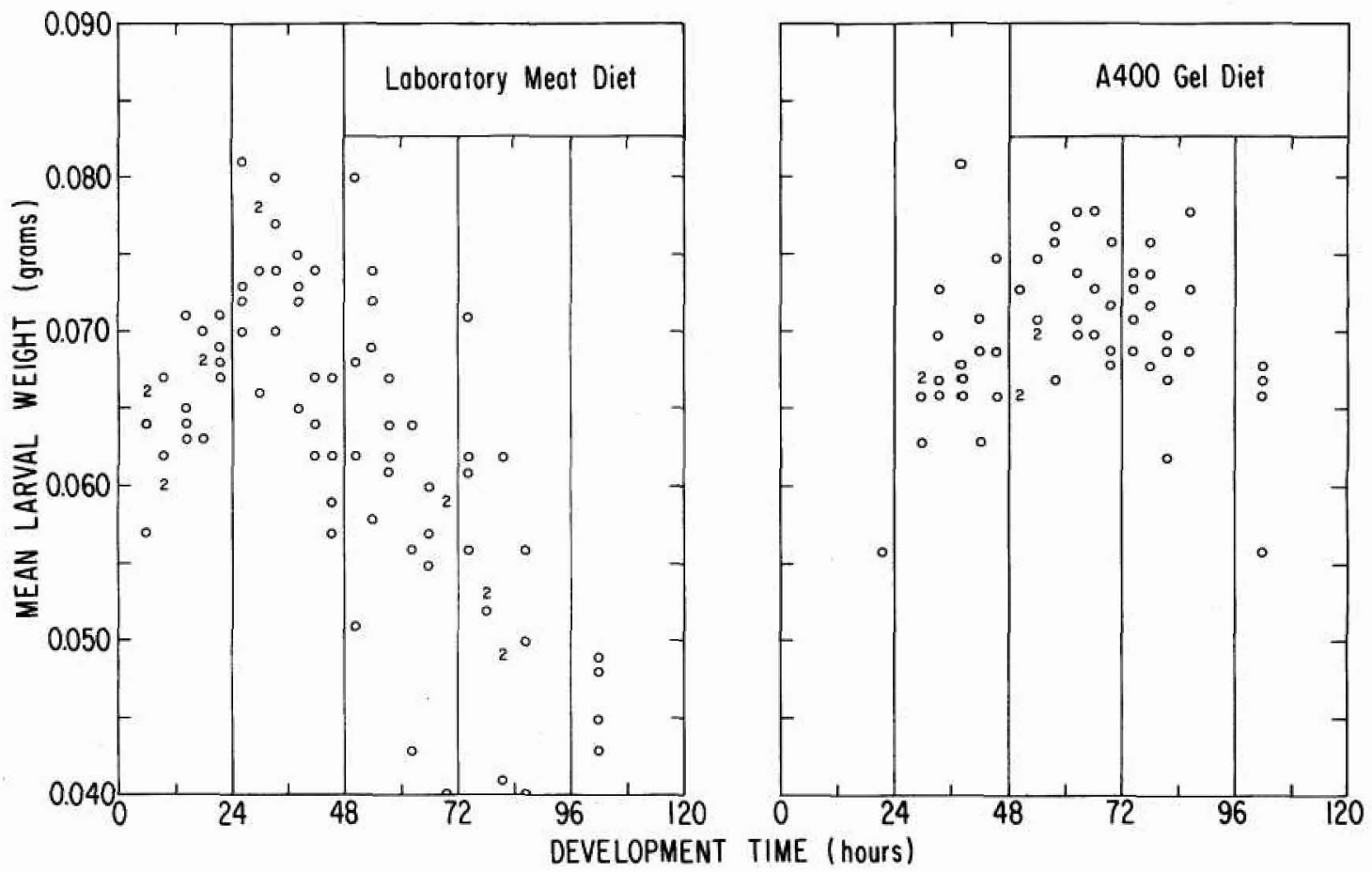

Fig. 1. Larval weight distribution profiles for samples taken every $2 \mathrm{~h}$ during crawl-off period on meat and gelled diets. Average mean weight for each of the four replicates is plotted against elapsed time since the first larvae migrated from the medium for pupation.

reared on gel continued to feed for 71.75 ( $\mathrm{SD}=$ 4.96) $\mathrm{h}$.

Effects of isolines were significant for determining larval weight $(F=2.45 ; \mathrm{df}=8,27 ; P=0.04)$ and number of larvae produced $(F=3.98$; $\mathrm{df}=$ $8,27 ; P=0.003)$ but not for average development time $(F=1.29 ; \mathrm{df}=8,27 ; P=0.29)$. Data in Table 4 show the extent of variation among isolines for these traits (for each line, the data given are means or totals for two replications).

\section{Discussion}

Comparison of meat and G-400 gelled diets for a laboratory-adapted strain indicated that the gelled diet produced larvae of a size and yield equal to, or greater than, the standard meat diet. These results confirm those of Harris et al. (1984, 1985). In addition, the between-generation variability that plagues many laboratory studies of screwworms (Hammack 1984) was greatly re-

Table 3. Rearing data for effect of diet on VF-84 serewworms (ANOVA tests the effect of diet individually; MANOVA tests the effeet of diet with interacting parameters)

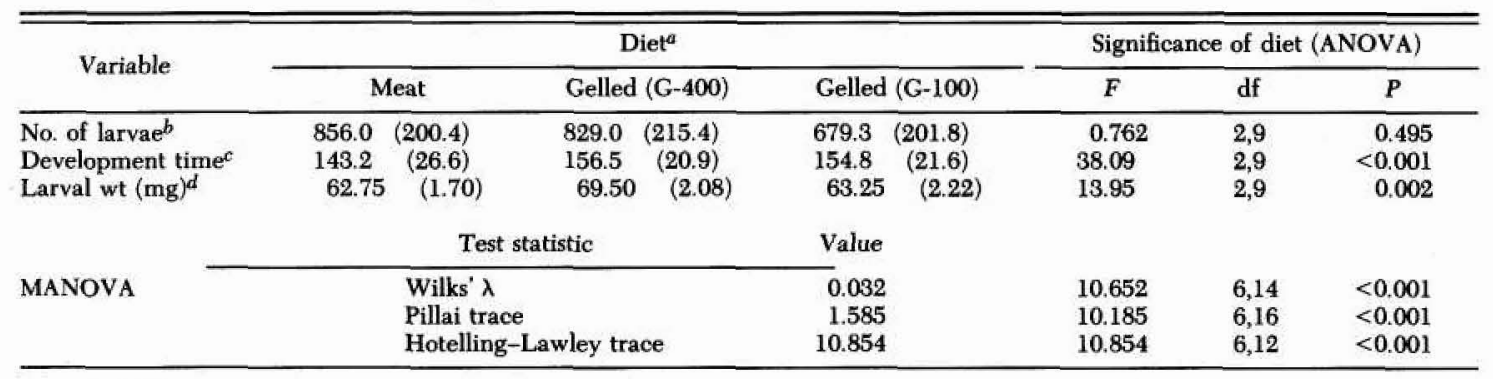

a (SD); four repetitions.

$b$ Analysis performed using total larval production for each group (four replicates).

- Analysis performed using individual hourly samples for each group.

$d$ Sum of sample mean weight (milligrams)/number of samples. 
Table 4. Weight of larvae leaving rearing media for pupation (crawl-off) for meat and gelled diets (lines are nine isofemale lines, second-generation larvae from Chetumal, Quintana Roo, Mexico)

\begin{tabular}{|c|c|c|c|c|c|c|}
\hline \multirow{2}{*}{ Line } & \multicolumn{3}{|c|}{ Meat } & \multicolumn{3}{|c|}{ Gel } \\
\hline & $n$ & $\bar{x} w t^{a}$ & $\hat{x}$ sample $w^{b}(\mathrm{SD})$ & $n$ & $\bar{x}$ total $w^{d}$ & $x$ sample $w^{b}(\mathrm{SD})$ \\
\hline 1 & 1,152 & 58.64 & $55.90(7.44)$ & 1,317 & 56.79 & $57.62(5.91)$ \\
\hline 2 & 1,326 & 64.52 & $58.96(8.58)$ & 1,231 & 56.70 & $57.43(6.83)$ \\
\hline 3 & 1,272 & 61.02 & $59.55(5.88)$ & 1,515 & 68.53 & $71.42(7.75)$ \\
\hline 4 & 167 & 67.53 & $63.06(7.54)$ & 453 & 64.20 & $63.44(7.00)$ \\
\hline 5 & 797 & 64.36 & $59.24 \quad(9.35)$ & 847 & 65.67 & $63.17(8.42)$ \\
\hline 6 & 848 & 66.39 & $60.33(11.92)$ & 1,337 & 59.86 & $60.71(5.00)$ \\
\hline 7 & 416 & 62.20 & $63.57 \quad(4.29)$ & 918 & 56.56 & $57.40(5.29)$ \\
\hline 8 & 643 & 64.02 & $58.91 \quad(8.23)$ & 1,104 & 62.50 & $61.20(7.56)$ \\
\hline 9 & 87 & 41.62 & $42.10(7.34)$ & 396 & 62.77 & $61.09(5.16)$ \\
\hline Total & 6,708 & 62.67 & & 9,118 & 61.43 & \\
\hline
\end{tabular}

a Weight of all larvae produced/number of larvae produced.

${ }^{b}$ Mean of mean sample weights of larvae collected every $4 \mathrm{~h}$ for total crawl-off period.

duced with the gelled diet. Larvae reared on the gelled diet required ca. $13 \mathrm{~h}$ (Table 3 ) longer to complete their development than those reared on the meat diet. The inferiority of the G-100 gel suggested that a less uniform gelling agent led to reduced size and yield. Our experience indicates that if G-400 gel was not mixed well or was mixed at low temperatures $\left(<20^{\circ} \mathrm{C}\right)$, an inferior medium resulted.

Rearing profiles on the G-400 gelled and meat diets indicated that mean larval size varied less for gelled diet during the 3-d crawl-off period. Also, comparison of mean weight ranges $30-40 \mathrm{~h}$ after the initiation of crawl-off showed that larvae were about equal in weight at that time for the two diets. Because no fresh diet was added or waste removed after the 4 th $\mathrm{d}$, larvae in meat diet may have been leaving the media to escape toxic wastes, while larvae on gelled diet continued to feed.

Newly colonized isofemale lines showed characteristically low survival and small size typical of lines undergoing laboratory adaptation. Size varied considerably between lines and no clear relationship between larval size and density was observed. The effect of isolines as factors in determining larval size within each diet type indicated that quality-control screening within a generation or rearing group can be effective on gelled as well as meat diets. However, the reduced variability between generations made the gelled diet more appropriate for monitoring fly quality over time. Reduced variability and improved uniformity of the gelled diet made it more suitable for studies on screwworm nutrition and physiology. In addition, the gelled medium approximated the liquid medium used for screwworm mass production more closely than did the meat diet. Thus, laboratory findings were more relevant to the eradication program, and techniques developed on the gel diet could be transferred to the mass-production facility more rapidly.

Additional advantages of the gelled diet for laboratory rearing included reduced labor and food costs $(\$ 1.35$ per pan for the meat diet versus $\$ 0.35$ per pan for the Water-Lock G- 400 gelled diet) and improved laboratory cleanliness and environment. Removing old diet from the meat substrate required care in separating larvae from ammoniaand sulfide-laden rotting meat and more than doubled the labor per feeding on meat diet. The increased handling required for removing the waste media also increased the possibility of transferring larvae between pans (interline contamination). A similar procedure was not necessary with the gelled diet. The gelling agent appeared to absorb the metabolic wastes and, thus, reduced the odor emitted during larval rearing. In addition, because the used gel medium remained semisolid, disposal was facilitated.

\section{Acknowledgment}

We thank D. L. Bailey, R. L. Harris, N. C. Leppla, and C. J. Whitten for their helpful suggestions and critical reading of the manuscript.

\section{References Cited}

Brown, H. E. \& J. W. Snow. 1979. Screwworms (Diptera: Calliphoridae): a new liquid medium for rearing screwworm larvae. J. Med. Entomol. 16: 2932.

Gingrich, R. E., A. J. Graham \& B. G. Hightower. 1971. Media containing liquefied nutrients for massrearing larvae of the screw-worm. J. Econ. Entomol. 64: 678-683.

Hammaek, L. 1984. Relationships of larval rearing variables to fly attraction and oviposition responses in the screwworm, Cochliomyia hominivorax (Diptera: Calliphoridae). J. Med. Entomol. 21: 351-356.

Harris, R. L., R. D. Peterson III, M. E. Vasquez-Guevara \& O. H. Graham. 1984. Gelled media for the production of screwworm larvae. Southwest. Entomol. 9: 257-262.

Harris, R. L., E. F. Gersabeck, C. Corso \& O. H. Graham. 1985. Screwworm larval production on gelled media. Southwest. Entomol. 10: 253-256.

Melvin, R. \& R. C. Bushland. 1936. A method of rearing Cochliomyia americana $\mathrm{C}$. \& $\mathrm{P}$. on artificial 
media. U.S. Dep. Agric. Bur. Entomol. Plant Quar. Rep. ET-88.

1940. The nutritional requirements of screwworm larvae. J. Econ. Entomol. 33: 850-852.

Morrison, D. F. 1976. Multivariate statistical methods. McGraw-Hill, New York.
Wilkinson, L. 1986. SYSTAT, the system for statistics (version 2). SYSTAT, Inc., Evanston, Ill.

Received for publication 4 August 1986; accepted 31 October 1986. 